\title{
Characteristics of Range of Motion among Women Pro Baseball Players: A Comparison with University Men
}

\author{
Machiko Hiramoto1,2, Toru Morihara ${ }^{3}$, Tomoyuki Matsui ${ }^{1,2}$, Yoshikazu Azuma ${ }^{1}$, Kazuya Seo $^{4}$, \\ Tetsuya Miyazaki ${ }^{4}$, Toshiaki Eto ${ }^{5}$, Yuya Watanabe6, Takeshi Sukenariं ${ }^{3}$, Yosuke Yamada7, \\ Shuhei Morifusa ${ }^{1}$, Noriyuki Kida ${ }^{2}$ \\ ${ }^{1}$ Marutamachi Rehabilitation Clinic, Rakuwa Medical Sports Kyoto, Kyoto, Japan \\ ${ }^{2}$ Graduate School of Science and Technology, Kyoto Institute of Technology, Kyoto, Japan \\ ${ }^{3}$ Department of Orthopedics, Graduate School of Medical Science, Kyoto Prefectural University of Medicine, Kyoto, Japan \\ ${ }^{4}$ Rehabilitation Unit, University Hospital, Kyoto Prefectural University of Medicine, Kyoto, Japan \\ ${ }^{5}$ Department of Rehabilitation, Fushimi Okamoto Hospital, Kyoto, Japan \\ ${ }^{6}$ Faculty of Health and Sports Science, Doshisha University, Kyoto, Japan \\ ${ }^{7}$ Department of Nutritional Science, National Institute of Health and Nutrition, National Institutes of Biomedical Innovation, \\ Health and Nutrition, Tokyo, Japan \\ Email: true.to.your.heart810@gmail.com
}

How to cite this paper: Hiramoto, M. Morihara, T., Matsui, T., Azuma, Y., Seo, K., Miyazaki, T., Eto, T., Watanabe, Y. Sukenari, T., Yamada, Y., Morifusa, S., \& Kida, N. (2017). Characteristics of Range of Motion among Women Pro Baseball Players: A Comparison with University Men. Advances in Physical Education, 7, 418-424. https://doi.org/10.4236/ape.2017.74035

Received: September 26, 2017

Accepted: November 6, 2017

Published: November 9, 2017

Copyright $\odot 2017$ by authors and Scientific Research Publishing Inc. This work is licensed under the Creative Commons Attribution International License (CC BY 4.0).

http://creativecommons.org/licenses/by/4.0/

\begin{abstract}
The purpose of this study was to measure range of motion among professional women baseball players and to identify specific attributes through comparison against university men players. Subjects were 53 professional women baseball players (average age $21.9 \pm 2.9$ years) and 23 university men baseball players (19.8 \pm 0.8 years). Measurement of shoulder external and internal rotation, neck and thoracolumbar rotation, hip internal and external rotation, SLR and HBD revealed sex differences and laterality. Women players had higher lower limb flexibility values compared with men, and like men, demonstrated laterality in range of motion in the limbs and trunk. Findings from this study may provide reference values that can be applied to women's conditioning programs.
\end{abstract}

\section{Keywords}

Range of Motion, Baseball, Women

\section{Introduction}

According to the Women's Baseball Federation of Japan, the women's regulation baseball population in Japan was 1811 as of February 2017. This pales in com- 
parison to a reported 168,000 players registered at member schools of the Japan High School Baseball Federation, but according to the Japan High School Girls Baseball Federation, the number of schools with girls' regulation baseball teams has steadily grown from just 5 in 2007 to 26 in 2016. The Japan Women's Baseball League was established in 2009, women's professional baseball was launched in 2010, and in 2016, Japan won its 5th consecutive championship in the IBAF Women's Baseball World Cup.

The literature on men's baseball includes studies on range of motion (Hiramoto et al., 2012) and muscle strength (Hayashida \& Nakagawa, 2005) as well as pitching motion analysis (Seo et al., 2013). In regard to women, however, there is only a scattering of studies on pain (Yonekawa, 2012) and pitching motion (Ito et al., 2004), and the attributes of range of motion are unclear. Since previous research has shown that throwing injury is related to trunk and lower limb flexibility (Hamada et al., 2009; Fujii et al., 2005) and laterality in the range of motion of the neck, thoracolumbar and hip joint (among high school boy's baseball players; Matsui et al., 2011; Matsui et al., 2013). For women athletes as well, it is necessary to clarify whether the left-right difference is important. Axial alignment of the lower limb has been reported to be different for men and women (Tamari et al., 2003), the range of motion may need to be considered by sex. The aim in this study is to contribute to improved performance among professional women players by identifying their physical attributes in terms of sex difference and laterality in range of motion.

\section{Method}

Subjects were 57 professional women baseball players registered with the Japan Women's Baseball League (average age $21.9 \pm 2.9$ years) and 24 university men baseball players belonging to the Kansai Big 6 Baseball League (19.8 \pm 0.8 years). Players who had shoulder or elbow pain or who were otherwise not in top pitching condition on the day of the medical checkup were excluded. 53 professional women baseball players and 23 university men baseball players finally took part in this study. A breakdown is shown in Table 1.

Measurement items were degree of external and internal rotation in the shoulder joint 2 nd position, degree of neck and thoracolumbar rotation (folded sitting position), degree of internal and external rotation in the hip joint (dorsal position, hip and knee joint 90 degree bent position), straight leg raising (SLR) angle, and heel buttock distance (HBD).

The method of measurement was consistent with the guidelines of The Japanese Orthopaedic Association Corporation and The Japanese Association of Rehabilitation Medicine (The Japanese Orthopaedic Association Corporation Physical Disability Committee, 1974; Yonemoto et al., 1995). SLR angle and HBD measurement are based on methods used by Kibler et al. (1989) and Torii et al. (1993). SLR angle is measured as the degree between the thigh and trunk axis when the subject is in a dorsal position with the opposite leg and pelvis stabilized, and with the legs in a neutral internal and external rotation position. HBD 
Table 1. Participant characteristics of women and men baseball players.

\begin{tabular}{ccc}
\hline & $\begin{array}{c}\text { professional women baseball players } \\
\mathrm{n}=53\end{array}$ & $\begin{array}{c}\text { college men baseball players } \\
\mathrm{n}=23\end{array}$ \\
\hline Age (years) & $21.9 \pm 2.9$ & $21.9 \pm 2.9$ \\
Height $(\mathrm{cm})$ & $162.9 \pm 5.1$ & $175.7 \pm 4.1$ \\
Weight $(\mathrm{kg})$ & $60.1 \pm 6.3$ & $72.9 \pm 4.3$ \\
Position & 16 & \\
Pitcher & 6 & 2 \\
Catcher & 20 & 5 \\
Infielder & 11 & 2 \\
Outfielder & & \\
\hline
\end{tabular}

Mean \pm standard deviation.

is measured as the distance from the buttocks to the heel when the subject is in an abdominal position with the pelvis stabilized and with hip joint in a neutral internal and external rotation and adduction and abduction position. Degree is measured in 1 degree increments using a University of Tokyo goniometer and distance is measured in $1 \mathrm{~mm}$ increments using a tape measure.

To prevent compensatory motion and limit measurement errors, measurement tasks were divided among 4 physical therapist examiners who were each in charge of manipulation, stabilizing positions, taking measurements and recording values. Movement axis, principle axis and measurement values were validated by all 4 examiners. To prevent examiner error, there was one booth for measurement of each item. We conducted two-factor analysis of variance with sex difference as an inter-subject factor and laterality as an inter-subject factor. A simple main effect test was conducted where there was interaction. We set the level of significance at 5\% and used IBM SPSS21 statistical software.

This study was explained to participants with approval from The Kyoto Prefectural University of Medicine Medical Ethics Committee and conducted with full consent thereof. All participants provided written informed consent.

\section{Results}

With respect to basic statistics and sex difference and laterality for each range of motion, there was significant interaction for shoulder internal rotation. Analysis of simple main effect revealed that for shoulder internal rotation, non-pitching side values were significantly higher than the pitching side among both women and men. There was no significant difference by sex for either non-pitching side or pitching side.

Analysis of main effect for non-significant interaction revealed a significant main effect for sex difference in hip internal rotation, SLR and HBD. Values were significantly high for hip internal rotation and SLR among women players and for HBD among men players. There was also a significant main effect for laterality in shoulder external rotation, neck rotation, thoracolumbar rotation, hip 
external rotation, and HBD. Further, the pitching side had significantly high values compared to the non-pitching side for shoulder external rotation and hip external rotation, while the non-pitching side had significantly high values compared to the pitching side for neck rotation, thoracolumbar rotation and HBD (Table 2).

\section{Discussion}

This study attempts to identify the attributes of range of motion in consideration of skeletal and muscular differences between men and women baseball players. University men players were selected as a comparison group as they were in roughly the same age group.

Results suggest a sex difference where women players had significantly higher values for hip internal rotation, SLR and HBD items compared to men. Since previous studies have reported that healthy women in the general population have high values for hip internal rotation and SLR angle (Okabe et al., 1980; Idota \& Yoshida, 1991), top level Japanese women track athletes have higher values for hip internal rotation and SLR angle and lower values for HBD compared to men (Takahashi et al., 2012), and elite women tennis players have higher values for hip internal rotation compared to men (Ellenbecker et al., 2007), we assume that greater range of motion and flexibility among women compared to men for hip internal rotation, SLR and HBD items is a sex difference as opposed to an attribute of the sport.

Left and right comparison revealed a significant difference for shoulder external and internal rotation, neck and thoracolumbar rotation, hip external rotation, and HBD items. This is consistent with other findings that shoulder external rotation is larger on the pitching side and internal rotation is larger on the

Table 2. Range of motion of women and men baseball players.

\begin{tabular}{|c|c|c|c|c|c|c|c|}
\hline & \multicolumn{2}{|c|}{ Women players } & \multicolumn{2}{|c|}{ Men players } & \multicolumn{2}{|c|}{ Main effect } & \multirow[t]{2}{*}{ Interaction } \\
\hline & pitching side & $\begin{array}{c}\text { non-pitching } \\
\text { side }\end{array}$ & pitching side & $\begin{array}{c}\text { non-pitching } \\
\text { side }\end{array}$ & sex & laterality & \\
\hline & $\mathrm{M} \pm \mathrm{SD}$ & $\mathrm{M} \pm \mathrm{SD}$ & $\mathrm{M} \pm \mathrm{SD}$ & $\mathrm{M} \pm \mathrm{SD}$ & $F$ value & $F$ value & $F$ value \\
\hline $\begin{array}{c}\text { Shoulder } \\
\text { ER }\end{array}$ & $133.8 \pm 8.6$ & $122.4 \pm 7.2$ & $134.7 \pm 9.6$ & $121.4 \pm 7.9$ & 0.001 & $114.46^{\star *}$ & 0.59 \\
\hline Shoulder IR & $30.7 \pm 9.3$ & $44.6 \pm 10.5$ & $26.0 \pm 11.1$ & $45.6 \pm 8.8$ & 0.73 & $188.62^{* *}$ & $5.48^{\star}$ \\
\hline $\begin{array}{c}\text { Neck } \\
\text { Rotation }\end{array}$ & $91.9 \pm 6.8$ & $94.6 \pm 8.1$ & $91.8 \pm 4.6$ & $96.6 \pm 5.6$ & 0.44 & $17.63^{\star \star}$ & 0.14 \\
\hline $\begin{array}{c}\text { Trunk } \\
\text { Rotation }\end{array}$ & $53.8 \pm 8.0$ & $57.6 \pm 9.0$ & $58.0 \pm 8.2$ & $60.6 \pm 7.7$ & 3.73 & $12.10^{\star *}$ & 0.47 \\
\hline Hip ER & $57.0 \pm 9.6$ & $54.6 \pm 9.1$ & $58.2 \pm 8.6$ & $56.4 \pm 7.3$ & 0.59 & $4.06^{*}$ & 0.11 \\
\hline Hip IR & $48.7 \pm 11.0$ & $49.5 \pm 10.5$ & $35.6 \pm 6.8$ & $37.9 \pm 7.6$ & $30.74^{* *}$ & 2.34 & 0.46 \\
\hline SLR & $71.1 \pm 10.9$ & $71.2 \pm 10.9$ & $58.0 \pm 9.1$ & $61.5 \pm 6.9$ & $23.20^{* *}$ & 3.76 & 0.33 \\
\hline $\mathrm{HBD}$ & $4.34 \pm 3.02$ & $4.78 \pm 3.48$ & $6.47 \pm 3.46$ & $7.43 \pm 3.33$ & $10.86^{\star *}$ & $9.01^{\star *}$ & 1.44 \\
\hline
\end{tabular}

${ }^{\star} p<0.05 ;{ }^{* *} p<0.01 ; \mathrm{ER}$, external rotation; IR, internal rotation. 


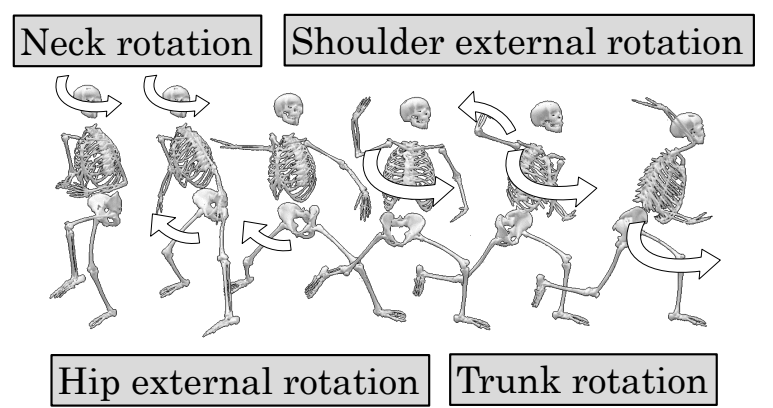

Figure 1. Pitching motion.

non-pitching side (Brown et al., 1988; Bigliani et al., 1997; Ellenbecker et al., 2002; Meister et al., 2005). Our results are also consistent with an earlier study we conducted of junior high and high school boys' baseball pitchers in which we found that neck and thoracolumbar range of motion was larger on the non-pitching side (Hiramoto et al., 2012; Matsui et al., 2011).

In regard to hip rotation range of motion, Nishino et al. (2012) found no laterality among pitchers aged 11 to 18 years old. Among professional baseball pitchers, however, Robb et al. (2010) found that hip rotation range of motion was greater on the pitching side. In this study, our analysis suggests laterality in hip external rotation angle. The windup is a repetitive, one-directional motion involving the legs, torso, and arms (Figure 1). The neck rotates to the non-pitching side in the windup stage, the hip joint on the pitching side rotates externally in the early corking stage, and the thoracolumbar rotates to the non-pitching side while the hip joint on the non-pitching side rotates internally in the late corking and follow-through stages. We therefore assume that laterality in the neck, shoulder, thoracolumbar, and hip are attributes of the sport.

In this study, we have identified range of motion attributes for women players as opposed to men and proposed standard values that may be applied in rehabilitation and conditioning settings. ACL re-injury is reported to be higher in women athletes than men athletes (Schilaty et al., 2017). It is important to clarify the characteristics of women players and use them for prevention of disability. It is possible to present the target value of stretch as a women player to athletes and trainers. Of course, the physical attributes of women players cannot be described in terms of range of motion alone. Upper leg strength, body composition, field battery and other physical factors should also be considered along with further analysis of pitching motion in future studies.

\section{Conclusion}

Range of motion was measured among professional women baseball players and university men baseball players. Women players had higher flexibility scores in the legs compared with men players. Like men players, women players had range of motion laterality in the limbs and trunk. Findings from this study may provide reference values for conditioning among women players. 


\section{References}

Bigliani, L. U., Codd, T. P., Connor, P. M., Levine, W. N., Littlefield, M. A., \& Hershon, S. J. (1997). Shoulder Motion and Laxity in the Professional Baseball Player. The American Journal of Sports Medicine, 25, 609-613. https://doi.org/10.1177/036354659702500504

Brown, L. P., Niehues, S. L., Harrah, A., Yavorsky, P., \& Hirshman, H. P. (1988). Upper Extremity Range of Motion and Isokinetic Strength of the Internal and External Shoulder Rotators in Major League Baseball Players. The American Journal of Sports Medicine, 16, 577-585. https://doi.org/10.1177/036354658801600604

Ellenbecker, T. S., Ellenbecker, G. A., Roetert, E. P., Silva, R. T., Keuter, G., \& Sperling, F. (2007). Descriptive Profile of Hip Rotation Range of Motion in Elite Tennis Players and Professional Baseball Pitchers. The American Journal of Sports Medicine, 35, 1371-1376. https://doi.org/10.1177/0363546507300260

Ellenbecker, T. S., Roetert, E. P., Bailie, D. S., Davies, G. J., \& Brown, S. W. (2002). Glenohumeral Joint Total Rotation Range of Motion in Elite Tennis Players and Baseball Pitchers. Medicine \& Science in Sports \& Exercise, 34, 2052-2056.

https://doi.org/10.1097/00005768-200212000-00028

Fujii, Y., Togo, Y., Maeda, M., Fukushuima, K., Kakoi, H., \& Ogura, T. (2005). The Characteristic of the Trunk Rotation in the Throwing Athletes. The Shoulder Joint, 29, 663-666.

Hamada, J., Fujita, K., Igarashi, E., Endo, K., \& Yano, Y. (2009). Longitudinal Study of Shoulder and Elbow Disorder in High School Baseball Players. The Shoulder Joint, 33, 519-522.

Hayashida, K., \& Nakagawa, S. (2005). Influence of Internal and External Rotation Strength of the Shoulder on Shoulder Pain during Throwing in High School Baseball Pitchers. The Shoulder Joint, 29, 651-654.

Hiramoto, M., Hojo, T., Matsui, T., Azuma, Y., Seo, K., Shimizu, C., Kida, Y., Morihara, T., \& Hase, H. (2012). The Change of Range of Motion in Junior High School Baseball Players. Doshisha Journal of Health \&Sports Science, 4, 1-4.

Idota, H., \& Yoshida, T. (1991). Clinical Significance of the Straight-Leg-Raising Test. The Journal of the Japanese Orthopaedic Association, 65, 1035-1044.

Ito, H., Nakazato, K., Watarai, K., \& Nakajima, H. (2004). Characteristics of the Trunk Rotation Movement during Throwing Motion in Female Baseball Players: Trunk Rotation Movement and Throwing Injuries of the Upper Extremities. Japanese Journal of Clinical Sports Medicine, 12, 469-477.

Kibler, W. B., Chandler, T. J., Uhl, T., \& Maddux, R. E. (1989). A Musculoskeletal Approach to the Preparticipation Physical Examination: Preventing Injury and Improving Performance. The American Journal of Sports Medicine, 17, 525-531. https://doi.org/10.1177/036354658901700413

Matsui, T., Morihara, T., Azuma, Y., Seo, K., Hiramoto, M., Kida, Y., Takashima, M., Horii, M., \& Kubo, T. (2011). The Prediction of Pitching Injuries of the Shoulder and Elbow by Comparing the ROM between Dominant and Non-Dominant Side on Neck/Trunk Rotations and Hip Internal Rotation. Japanese Journal of Physical Fitness Sports Medicine, 31, 93-97.

Matsui, T., Morihara, T., Azuma, Y., Seo, K., Hiramoto, M., Kida. Y., Takashima, M., Horii, M., \& Kubo, T. (2013). The Prediction of Pitching Injuries of the Shoulder and Elbow by Comparing the ROM between Dominant and Non-Dominant Side on Neck/Trunk Rotations and Hip Internal Rotation. Japanese Journal of Physical Fitness 
Sports Medicine, 62, 223-226. https://doi.org/10.7600/jspfsm.62.223

Meister, K., Day, T., Horodyski, M., Kaminski, T. W., Wasik, M. P., \& Tillman, S. (2005). Rotational Motion Changes in the Glenohumeral Joint of the Adolescent/Little League Baseball Player. The American Journal of Sports Medicine, 33, 693-698. https://doi.org/10.1177/0363546504269936

Nishino, K., Yamamoto, N., Tanaka, M., Iokawa, T., Koga, Y., \& Arakawa, M. (2012). Biomechanical Research of the Prevention of Pitching Injuries among Junior Baseball Players by Medical Examination and Pitching Motion Analysis. Japanese Journal of Clinical Sports Medicine, 20, 79-86.

Okabe, T., Watanabe, H., \& Amano, T. (1980). The Range of Motion of the Extremities in Healthy Japanese People-The Difference according to the Sex. General Rehabilitation, 8, 41-56.

Robb, A. J., Fleisig, G., Wilk, K., Macrina, L., Bolt, B., \& Pajaczkowski, J. (2010). Passive Ranges of Motion of the Hips and Their Relationship with Pitching Biomechanics and Ball Velocity in Professional Baseball Pitchers. The American Journal of Sports Medicine, 38, 2487-2493. https://doi.org/10.1177/0363546510375535

Schilaty, N. D., Nagelli, C., Bates, N. A., Sanders, T. L., Krych, A. J., Stuart, M. J., \& Hewett, T. E. (2017). Incidence of Second Anterior Cruciate Ligament Tears and Identification of Associated Risk Factors from 2001 to 2010 using a Geographic Database. Orthopaedic Journal of Sports Medicine, 5. https://doi.org/10.1177/2325967117724196

Seo, K., Morihara, T., Matsui, M., Azuma, Y., Hiramoto, M., Kida, Y., Yamada, Y., Nakamura, Y., Hojo, T., Horii, M., \& Kubo, T. (2013). Three-Dimensional Motion Analysis in High School Pitchers Focused on the Dominant Lower Extremity. Japanese Journal of Clinical Sports Medicine, 21, 618-622.

Takahashi, S., Takashima, N., Hoshikawa, A., \& Okuwaki, T. (2012). A Large: Scale Survey of Muscle Tightness in Elite Japanese Runners. Japanese Journal of Clinical Sports Medicine, 20, 41-48.

Tamari, K., Tinley, P., \& Aoyagi, K. (2003). Gender and Age-Related Differences in Axial Alignment of the Lower Limb among Healthy Japanese Volunteers: Comparative and Correlation Study. Journal of the Japanese Physical Therapy Association, 6, 25-34. https://doi.org/10.1298/jipta.6.25

The Japanese Orthopaedic Association Corporation Physical Disability Committee (1974). Kansetsukadoikihyoji narabini sokuteiho. [The Japanese Committee.] Japanese Journal of Rehabilitation Medicine, 11, 127-132.

Torii, S. (1993). Orthopedic Check-Up for Prevention of Athletic Injury in Adolescence-Relationship between the Change of Physique, Tightness and the Incidence of Injury. Japanese Journal of Orthopaedic Sports Medicine, 12, 239-243.

Yonekawa, S., Hattori, M., Qatanabe, M., \& Kuriyama, S. (2012). Pitching Disability of Shoulder and Elbow in Japanese Women Baseball Players. Japanese Journal of Orthopaedic Sports Medicine, 32, 70-73.

Yonemoto, K., Ishigami, J., \& Kondo, T. (1995). Measurement Method for Range of Joint Motion. Japanese Journal of Rehabilitation Medicine, 32, 207-217.

https://doi.org/10.2490/jjrm1963.32.207 